\title{
Non-destructive testing techniques applied to the masonry and timber structures of the Crocifisso Church in Noto
}

\author{
L. Binda, L. Cantini, P. Condoleo \& A. Saisi \\ DIS - Department of Structural Engineering, Politecnico of Milan, Italy
}

\begin{abstract}
After the partial collapse of the Cathedral of Noto in Sicily, damaged by the 1990 earthquake, which hit the oriental part of the Italian island, an extensive investigation carried out on site and in the laboratory allowed the detection of a pre-existing damage of the pillars due to long term behaviour of the material under compressive stresses. The investigation extended to other churches and buildings showed cases of progressive damage, which can in an unknown time, bring the structures to sudden collapse. This paper presents and discusses the preliminary results of the research carried out by the authors on the Crocifisso Church in Noto, built in the same period and with material similar to that of the Cathedral. The investigation programme was planned, aimed at evaluating the state of damage of the structure and at designing the preservation and restoration actions.

Keywords: diagnosis, on site test, long-term behaviour.
\end{abstract}

\section{Introduction}

The dramatic collapse of the central nave and of part of the dome of the Noto Cathedral (Fig. 1) damaged by the 1990 earthquake, took place only six years later, in 1996 (De Benedictis et al [1]). The accurate on site and laboratory investigation confirmed that the earthquake was only worsening the situation of the materials and of the structure which was already highly damaged (Binda et al $[2,3]$ ). The removal of the plaster (which was made in the 1960s) from the remaining pillars of the central nave revealed the pre-existence of a diffused distribution of vertical cracks and spalling of the corners in the external leaf made with limestone (calcarenite) regular blocks (Fig. 2). In fact, these cracks 
had been filled with the gypsum mortars used for plastering [2]. The continuous damage of the masonry under high compressive stresses is considered to cause in long terms to the collapse. Other cases were found to fall under the same phenomenon as the collapse of the Civic Tower of Pavia in 1989 (Binda et al [4]), of the Goch bell tower in 1992 and recently, two towers in Belgium.

In fact, it has been demonstrated that the behaviour of masonry under the action of persistent loads can evolve in a relatively long time until collapse; this can happen under lower stress values than those corresponding to the nominal material strength obtained by a standard monotonic compression test. The phenomenon can start for some masonry type at $45-50 \%$ of the nominal strength value (Binda and Anzani [5]). The available experimental data collected up to now tend to show an evident increase of lateral deformations developed in time caused by the development of the typical vertical cracks due to compressive stresses. This dilation phenomenon, an apparent increase in volume, can lead to collapse due to crack propagation. The effects can also be coupled with synergetic stresses caused by cyclic wind action and temperature variation. Additional minor shocks, like storms, low intensity earthquakes, etc., may contribute to increase the damage. The damage can easily develop when the material used for the construction is rather weak (weak bricks and mortars with irregular joints, soft stones) or the technique of construction is such that the internal core of the masonry can settle and deform more than the external leaf. In all these cases the damage can start early, even few years after the construction or after some partial reconstruction or even repair and continue very slowly for decades, until a sudden collapse happens.

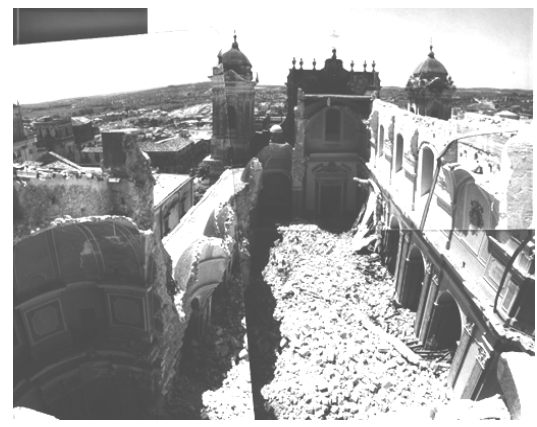

Figure 1: The Cathedral of Noto after the 1996 collapse.

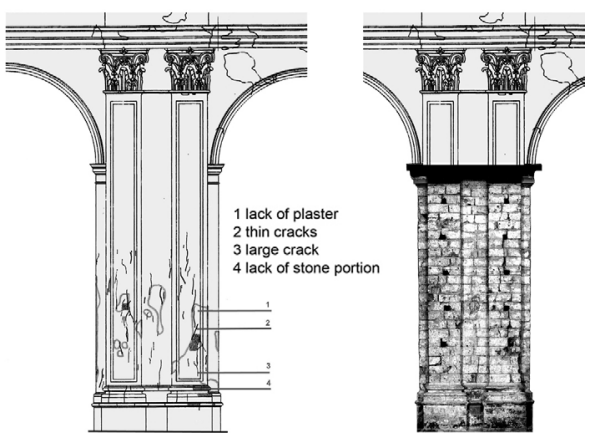

Figure 2: The damage survey of a Noto Cathedral pillar.

In the case of the Noto Cathedral, the internal rubble masonry of the pillars was found to be very weak [2]; its early higher deformation caused in the long range a high state of damage in the external stone leaf (Fig. 2). A further weakness was found in the materials used for the external leaf of the collapsed pillars. In fact while for the internal rubble filling the thick mortars joints were composed by hydrated lime and silt weak aggregates alternate with rather irregular courses of round river stones and there was a lack of connection 
between the internal rubble and external leaves, the external leaves were made of regularly cut blocks of a very weak travertine. These characteristics did certainly contribute to create weak load-bearing elements, which resulted in the long range highly stressed especially in the external leaves and the situation evolved toward increasing damage. The materials used and the construction technique of the load-bearing elements were both typical of the area; in fact the presence in the eastern part of Sicily of several quarries of limestone (also called "Noto stone") which could be easily carved, made this material very popular for the construction of churches, noble palaces and other monuments. In addition, the mortar aggregates were very frequently obtained from the same stones and quarries [2].

Several other churches and monuments are now under investigation to detect the extension of the phenomenon (Binda et al [6]). Among them, the Crocifisso Church in Noto was studied in order to evaluate its state of damage after the 1990 earthquake. The materials and technique of construction used for this church are very similar to the ones of the Noto Cathedral.

The investigation carried out on the structure of the Crocifisso church and here described, showed a diffused damage in the load-bearing elements, especially in the pillars of the nave, similar for materials and technique of construction to the ones of the Cathedral. Therefore, a quick repair and preventive intervention was necessary for the weakest parts.

\section{The Crocifisso Church: damage description}

After the earthquake of 1693 that destroyed the ancient city of Noto, the Crocifisso Church, placed in the highest part of the new town of Noto was built using the local limestone and finished in 1715. The façade (Fig. 3) and the interior show harmonious proportions, with rather slender pillars. A sequel of small domes covers the aisles; the central nave, instead, shows a barrel vault and a large dome. Above the barrel vault, a timber truss is present.

The church was built using the local limestone, the same as the one of the Cathedral and was finished in a relatively short time after the earthquake; also here, due to the mass of building in the new town, the construction was made by a poor workmanship. In Fig. 4 the Church vertical section is shown.

The church was damage by the 1990 earthquake, especially the transept and the domes of the lateral aisles and the vaults, which were therefore supported by provisional structures. The pillars, all covered with plaster and stuccoes, did not show apparently any damage.

On the contrary, during the first site inspection phase of the diagnosis an alarming state of damage was found in the pillars. The plaster, a thin one (4 to $5 \mathrm{~mm}$ thick) made by hydrated lime based mortar, was in fact hiding a pattern of vertical cracks in the stones continuing along the mortar joints. The reason was that the plaster was detached from the pillar surface and hence was hiding the real damage. After completely removing the plaster (made in the sixties), it was possible to perform a crack pattern survey of the pillars. 
The results of the experimental investigations are reported together with the suggested repair intervention in the following sections.
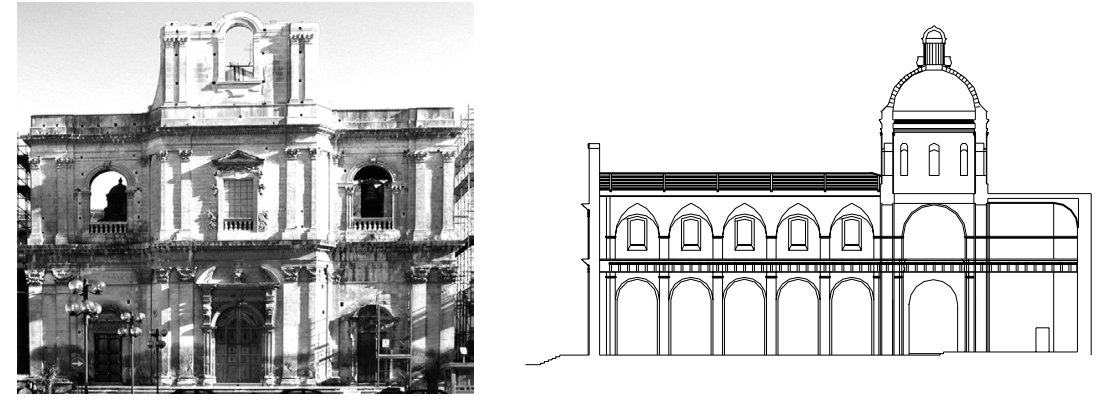

Figure 3: $\quad$ View of the façade Figure 4:

Longitudinal section of the of the Crocifisso Crocifisso Church. Church.

\subsection{Damage after the earthquake}

As said before, the Church was damaged by the 1990 earthquake, especially the transept, the domes of the aisles and the vaults, while the pillars, all covered with plaster and stuccoes apparently, did not show any damage. A simple calculation of the state of stress due to uniformly distributed stress for dead load gave 0.72 to $0.81 \mathrm{~N} / \mathrm{mm}^{2}$. The maximum compression value caused by horizontal forces plus dead load was calculated as 1.20 to $1.59 \mathrm{~N} / \mathrm{mm}^{2}$; apparently, the state of stress was not too high.

\section{Investigation program}

In view of a strengthening and repair intervention, an investigation program was planned. The program included the survey of the foundation typology by coring and boroscopy and the study of the damage of the masonry structures by flat jacks and sonic tests, mortar and stone characterisation (Binda et al [7]).

A survey was also performed on the timber truss of the roof, which had a very large dimension (almost 10 meters) and appeared to have some damage. Geometrical survey, penetrometry tests by resistograph and sonic tests were carried out on these structures in order to detect their state.

Fig. 5 shows the church plan with the localisation of the tests on the masonry.

\subsection{Masonry structures}

\subsubsection{Crack pattern survey}

As said above an alarming state of damage was found in the pillars, by locally removing the plaster. The plaster, in fact, was hiding a complex of vertical cracks passing through the stones and continuing along the mortar joints (Fig. 6).

This plaster was probably not born with the church, but only attached in the 1960 s as for other churches in Noto. Furthermore, after the removal, it was 
possible to detect that it was not well adherent to the masonry, also in absence of an adequate mechanical preparation of the support; in fact a dirty patina on the stones under the plaster itself was found.

The plaster was particularly thin (Fig. 7) and completely detached in the area in which deep cracks were distributed.

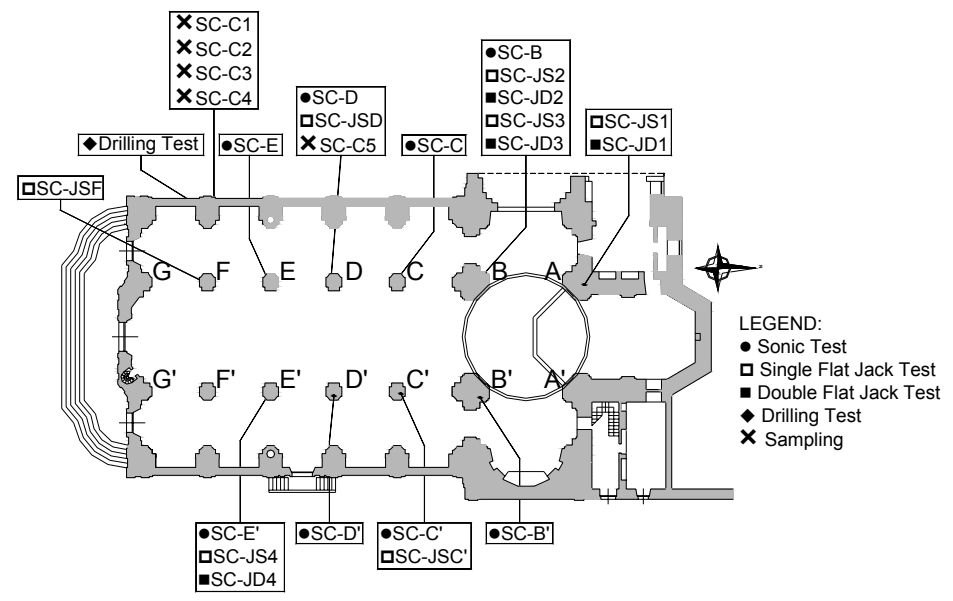

Figure 5: Crocifisso Church plan and localisation of the double flat-jack tests.

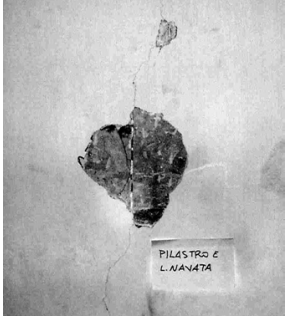

(a)

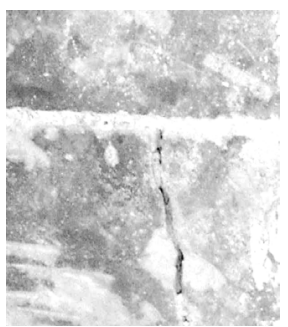

(b)

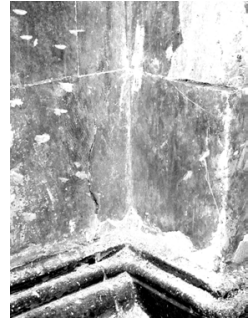

(c)

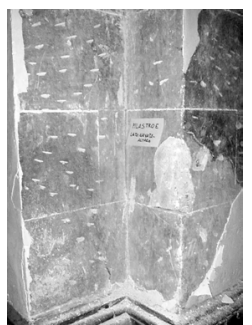

(d)

Figure 6: (a) The plaster did not show cracks; (b), (c), (d) damages visible after the plaster removal.

The pillars as in the case of the Noto Cathedral were built with an external leaf made of "Noto stone" regular blocks and internal filling with rubble masonry; the technique of construction is similar to the one of the Cathedral pillars, but the internal rubble seemed to be better built. After the recognition of the damages, the removal of the plaster from all the pillars up to $3 \mathrm{~m}$ of height was planned in order to survey the crack pattern.

Figs. 8-10 show examples of the crack pattern of the pillars. As it possible to observe in Fig. 9, the cracks are diffused and interesting the whole prospect, with a concentration in the corners. 

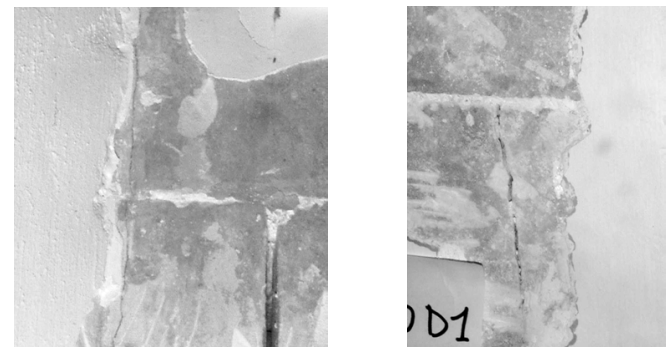

Figure 7: A very thin plaster (4-5 mm thick) made with lime-gypsum mortar covers the pillars, hiding the cracks.
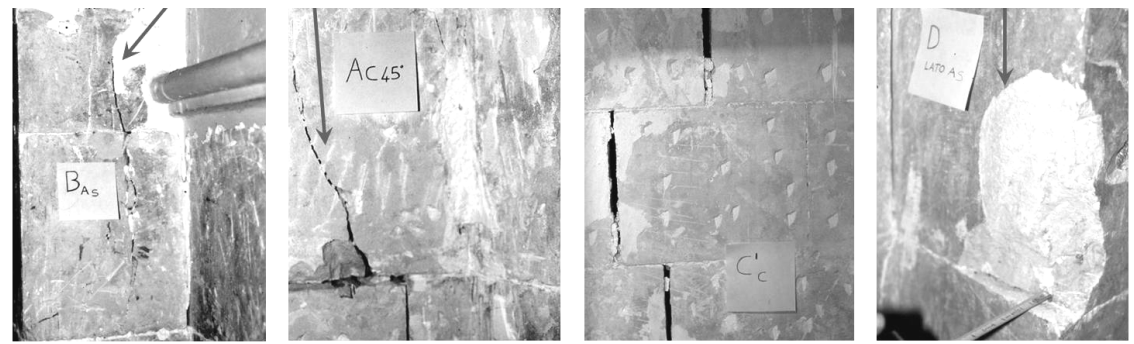

Figure 8: Example of damages: (a), (b) vertical cracks of the stone-blocks, (c) empty vertical joints (d) lack of material.
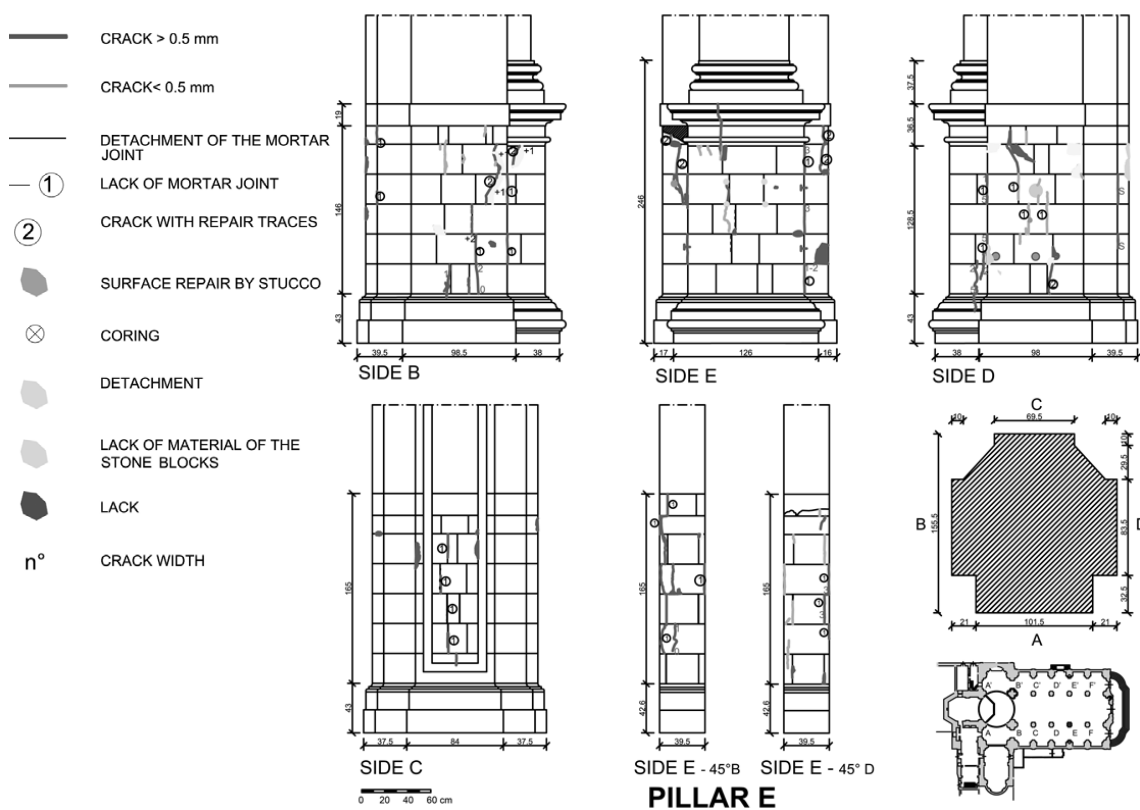

Figure 9: Crocifisso Church. Crack pattern of the base of the pillar E (Fig. 5). 


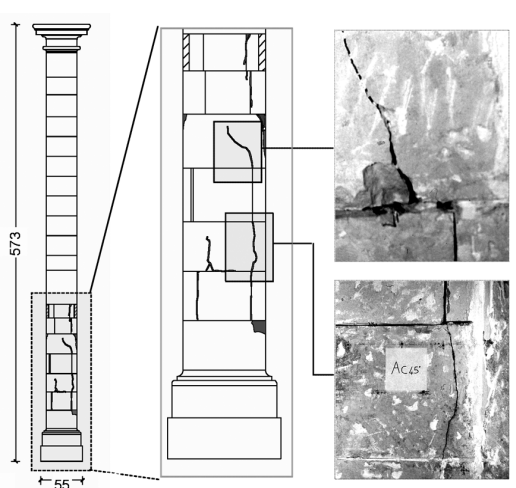

(a)

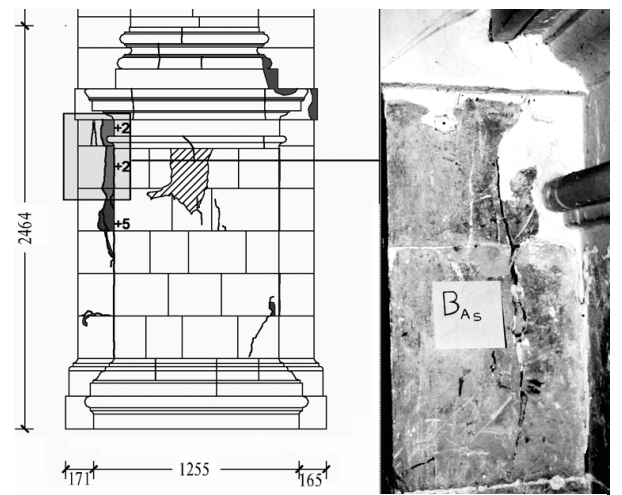

(b)

Figure 10: Crack pattern survey and detail of the pillars B (a) and C (b) (Fig. 5).

In some cases, the fissures were filled with mortar and the corners reconstructed (Fig. 8 and 9) with mortar. This fact suggests that the crack pattern was present before the plaster was applied.

The strengthening design was urgently changed and the pillars were urgently confined by stainless steel cross-shaped reinforcements confining the pillars at every two courses.

\subsubsection{NDT on the pillars}

The coring and the boroscopy observation, which together with the stone disposal survey gave information on the section morphology, revealed a multiple leaf masonry (see also Fig. 5). The internal masonry, as said above, is a rubble one, composed of a rather weak mortar, pieces of limestone (Fig. 11).

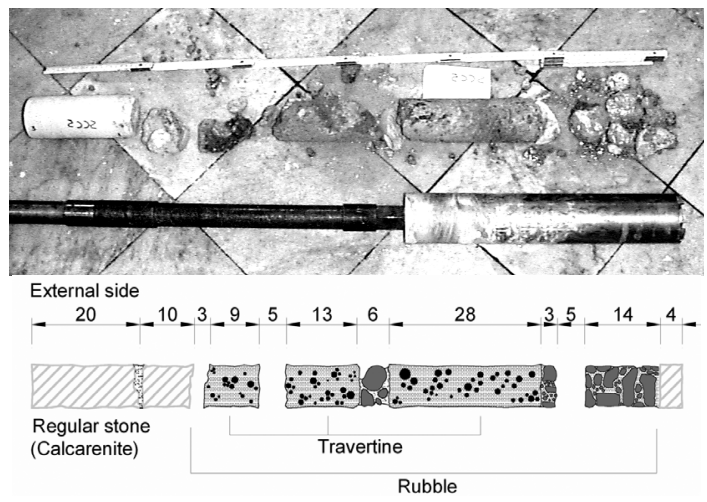

Figure 11: Drilled core of pillar C (Fig. 5) and re-construction.

3.1.2.1 Pulse Sonic tests Pulse sonic tests were carried out in order to detect the pillars characteristics. Fig. 12 shows typical sonic test results. The sonic 
velocities are higher in coincidence with the external stone leaves and lower when the impulse crosses the internal rubble filling, as expected. These results confirm what found by coring (Fig. 11).

The sonic velocity also is lowered by the presence of cracks, when they are perpendicularly crossed. In fact the lowest average velocities (SC-D1) concern the pillar called D (Fig. 5), characterised by the worst crack pattern situation. It was also possible to notice that in the case of highly cracked external leaf the velocity became lower.

The sonic tests once again confirmed to be efficient to detect difference in density of the material (i.e. rabble filling of pillars) and presence of cracks. This possibility avoids the use of destructive and invasive tests also allowing for the investigation on large surfaces of masonry.

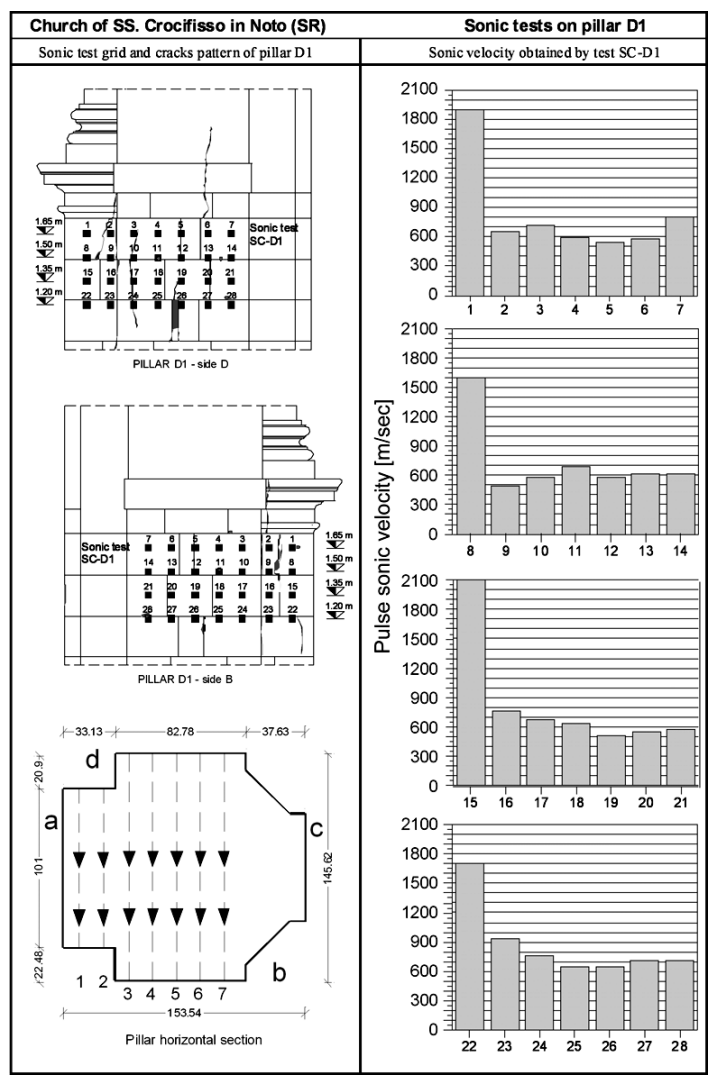

Figure 12: Crocifisso Church: results of sonic tests applied to the pillar D1 (Fig. 5).

3.1.2.2 Flat jack tests Flat jack, single and double, supplied interesting information. First of all, the state of stress was lower and non symmetrical in the pillars supporting the dome, with a value of 0.76 and $1.04-1.09 \mathrm{MPa}$, 
respectively (Fig. 5) in the apse pillar (SC-S1) and in the pillar toward the transept (SCJS2) (Fig. 14 and 15). The lower stress in the apse pillar is justified by the presence of wall portions, which support part of the loads.

Higher stress values, 1.39 MPa, were measured (SC-JS4) on a pillar called E1 (Fig. 5), while the other pillars have a lower stress (0.83-0.99 MPa). The stressstrain diagrams show consistent deformability of the masonry with rather low values of the elastic modulus and hence also of the strength. Furthermore, the high diffusion of cracks caused to interrupt most of the tests. The double flat jack-tests carried out within two stones (LVDT 5,6,7) and across a mortar joint (LVDT 1,2,3,4) (Fig. 13), show a totally different deformation under the same stress when it is measured on the stones or across the joint.

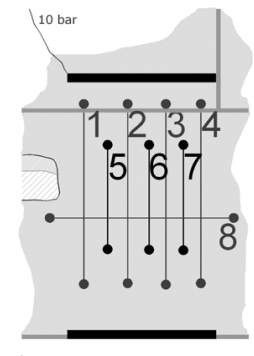

a)

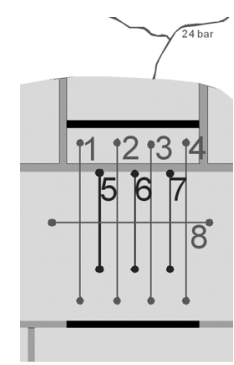

b)

Figure 13: Geometry of the double flat jack-tests SCD1 (a) and SCD2 (b). The acquisitions are carried out within two stones (LVDT 5, 6, 7) and across a mortar joint (LVDT 1, 2, 3, 4).

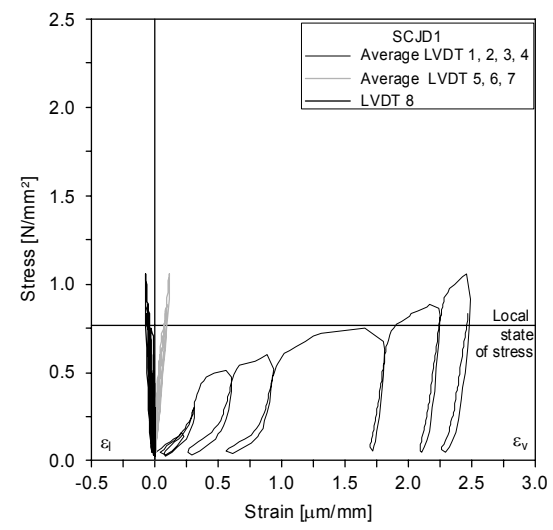

Figure 14: Flat-jack test result (test SC-D1 in Fig. 5).

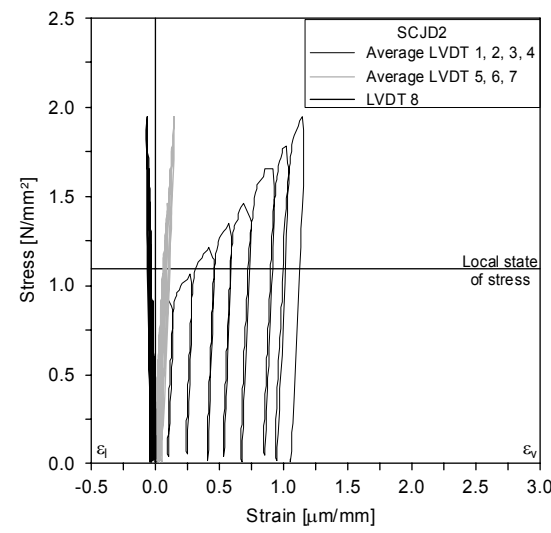

Figure 15: Flat-jack test result (test $\mathrm{SC}-\mathrm{D} 2$ in Fig. 5).

In Fig. 14 and 15 (SC-D1, SC-D2) these two different behaviour are shown in the stress-strain plot as average of LVDTs 1, 2, 3, 4 and of 5, 6, 7 (Fig. 13). 
It is then confirmed that there is a greater deformation in the joint when a certain state of stress is reached. Furthermore, the plot of Fig.14 shows a weaker behaviour of the masonry compared to SC-D2 (Fig. 15).

Nevertheless, in both cases the state of stress measured by the single flat-jack is outside the elastic range of the material. This explains also the detected damages.

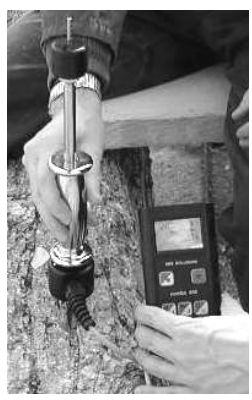

(a)

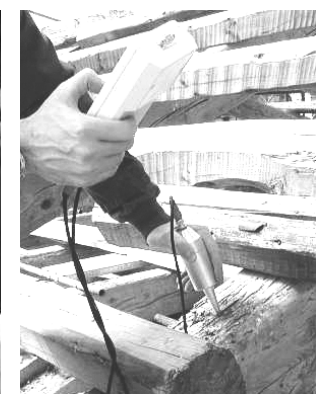

(b)

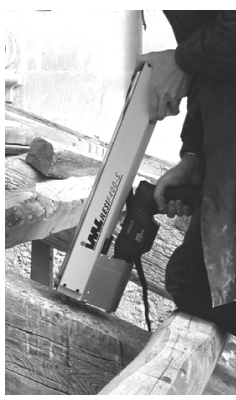

(c)

Figure 16: Testing the timber roof: thermo-hygrometric survey (a), ultrasonic test (b), penetrometric test on a truss element (c).

3.1.2.3 Material characterisation The used limestone, the "Noto Stone", is characterised by low mechanical properties especially in the case of saturated samples, as it was revealed by the compressive and splitting tests. Table 1 shows the mechanical results carried out on stones sampled from the walls of the Church. The mortar sampled from the pillars was submitted to chemical and optical tests and was defined as a hydrated lime based mortars.

Table 1: $\quad$ Mechanic characteristic of the Crocifisso stones.

\begin{tabular}{|c|c|c|c|c|c|}
\hline \multicolumn{4}{|c|}{ Compressive Test } & \multicolumn{2}{|c|}{ Brazilian Test } \\
\hline Sample & $\begin{array}{c}\text { Ultimate } \\
\text { Stress } \\
{[\mathrm{MPa}]}\end{array}$ & $\begin{array}{c}\mathrm{E} \\
{[\mathrm{MPa}]}\end{array}$ & $\begin{array}{l}v(30- \\
60 \%)\end{array}$ & Sample & $\begin{array}{c}\text { Ultimate } \\
\text { Stress } \\
{[\mathrm{MPa}]}\end{array}$ \\
\hline \multicolumn{6}{|c|}{ Dry condition } \\
\hline$\overline{\mathrm{SCC} 2 \mathrm{i}}$ & 16.1 & 11000 & 0.15 & SCC5 & 2.27 \\
\hline SCC4i & 19.1 & 12150 & 0.17 & $\mathrm{SCC} 3$ & 2.09 \\
\hline \multicolumn{6}{|l|}{ Saturated } \\
\hline $\mathrm{SCC} 2 \mathrm{e}$ & 10.7 & 7370 & 0.19 & SCC3 & 1.27 \\
\hline SCC3i & 12.5 & 10000 & 0.16 & $\mathrm{SCC} 4 \mathrm{e}$ & 1.09 \\
\hline SCC5e & 10.3 & 9650 & 0.16 & & \\
\hline
\end{tabular}

\subsection{Tests on timber structures}

The tests carried out on the timber elements of the roof were aimed to assess the material density related to the humidity and to the timber specie. Initially, the 
thermo-hygrometric conditions in the testing points were recorded (Fig. 16(a)). Successively, the ultrasonic characterization was carried out in cross-section mode (Fig. 16(b)).

Finally, penetrometric tests were performed using an apparatus, commercially denominated Resistograph (RESIF400®) (Fig. 16(c), that measures the resistance opposed by the timber to the penetration of a pin which is rotating and penetrating at constant speed. This parameter is related to the material density, which of course is influenced by the presence of knots, irregularities, decay, etc.

For each truss structure, three profiles were collected on the horizontal element, one on each inclined element and another on the secondary elements as shown in Fig. 17(a)). As an example, a profile obtained on the end of a horizontal element is shown in Fig. 17(b)). In general, very few profiles, localized at the ends of the horizontal elements, showed internal discontinuities.

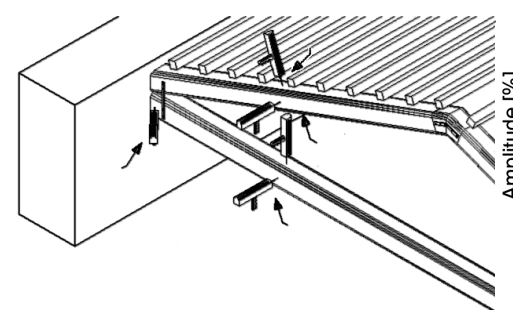

(a)

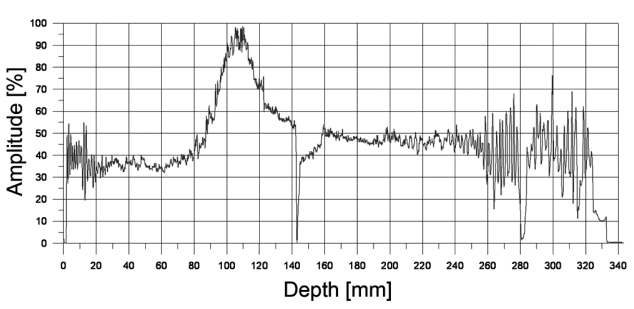

(b)

Figure 17: Penetrometric tests: localization of the tests (a); amplitude vs. depth profile (b).

\section{Conclusions}

The investigation carried out on the structures of the Crocifisso church was particularly important for both the timber and the masonry structures.

For the first ones it was decided that they could be preserved with few repair.

For the pillars, the situation was considered so difficult that it was suggested to carry out a repair intervention. The case in fact was very similar to the one of the Noto Cathedral. A partial collapse could take place under a next earthquake or due to the long-term behaviour of masonry without seismic events given the diffused damages shown by vertical diffused cracks of the studied pillars.

Even if in similar cases, it is suggested to monitor the structure for some years, in this particular case the work was done soon. The intervention was carried out on all the pillars by confining them at different height with appropriate steel confinements.

The results of visual inspection, survey and NDE tests once again showed the importance of a well-designed investigation to detect and understand the damage and its causes. 


\section{Acknowledgements}

The authors wish to thank directed by and the parish priest who supported the experimental investigation. The research was financed by the Genio Civile of Syracuse. C. Arcadi, M. Antico, M. Cucchi, M. Iscandri D. Penazzi, C. Tedeschi, C. Tiraboschi are gratefully acknowledged for their technical support; many thanks are also due to the students. Eng. Messina is gratefully acknowledged for his support from the Genio Civile.

\section{References}

[1] De Benedictis, R., Tringali, S., Gavarini, C., Binda, L. \& Baronio G., Methodology applied to the removal of the ruins and to the survey of the remains after the collapse of the Noto Cathedral in Sicily, Proc. of the 6th Int. Conf. Structural Studies, Repairs and Maintenance of Historical Buildings, STREMAH 99, Dresden, Germany, pp. 529-538, 1999.

[2] Binda, L., Saisi, A., C., De Benedictis, R. \& Tringali, S., Experimental study on the damaged pillars of the Noto Cathedral, 8th Int. Conf. on Structural Studies, Repairs and Maintenance of Heritage Architecture STREMAH 03, Halkidiki, Greece, pp. 89-98, 2003.

[3] Binda, L., Saisi, A. \& Tiraboschi, C. Application of sonic tests to the diagnosis of damaged and repaired structures, Non Destructive Testing and Evaluation Int., 34(2), pp. 123-138, 2001.

[4] Binda, L., Gatti, G., Mangano, G., Poggi, C. \& Sacchi Landriani, G., The collapse of the Civic Tower of Pavia: a survey of the materials and structure. Masonry International,6(1), pp. 11-20, 1992.

[5] Binda, L. \& Anzani, A. The time-dependent behaviour of masonry prisms: an interpretation. The Masonry Society Journal, 11(2), pp. 17-34, 1993.

[6] Binda, L., Saisi, A., Messina, S. \& Tringali, S., Mechanical damage due to long term behaviour of multiple leaf pillars in Sicilian Churches, Proc. of the III Int. Seminar: Historical Constructions, pp. 707-718, 2001.

[7] Binda, L., Saisi, A. \& Tiraboschi, C. Investigation procedures for the diagnosis of historic masonries, Construction and Building Materials, 14(4), pp. 199-233, 2000. 